\title{
Utilization of $\mathrm{CO} 2$ for syngas production by $\mathrm{CH} 4$ partial oxidation using a catalytic membrane reactor.
}

SHEHU, H., GOBINA, E., ORAKWE, I.

2019 


\title{
UTILIZATION OF $\mathrm{CO}_{2}$ FOR SYNGAS PRODUCTION BY $\mathrm{CH}_{4}$ PARTIAL OXIDATION USING A CATALYTIC MEMBRANE REACTOR
}

\author{
Habiba Shehu, Edward Gobina* and Ifeyinwa Orakwe \\ Center for Process Integration and Membrane Technology Robert Gordon University, School of Engineering Aberdeen, \\ United Kingdom \\ *Corresponding author e-mail: e.gobina@rgu.ac.uk
}

\begin{abstract}
In this research, a synthetic flue gas mixture with added methane was used as the feed gas in the process of dry reforming with partial oxidation of methane using a laboratory scale catalytic membrane reactor to produce hydrogen and carbon monoxide that can present the starting point for methanol or ammonia synthesis and Fischer-Tropsch reactions. 0.5\% wt\% Rh catalyst was deposited on a y-alumina support using rhodium (III) chloride precursor and incorporated into a shell and tube membrane reactor to measure the yield of synthesis gas $\left(\mathrm{CO}\right.$ and $\mathrm{H}_{2}$ ) and conversion of $\mathrm{CH}_{4}, \mathrm{O}_{2}$ and $\mathrm{CO}_{2}$ respectively. These measurements were used to determine the reaction order and rate of $\mathrm{CO}_{2}$. The conversion of $\mathrm{CO}_{2}$ and $\mathrm{CH}_{4}$ were determined at different gas hourly space velocities. The reaction order was determined to be a first-order with respect to $\mathrm{CO}_{2}$. The rate of reaction for $\mathrm{CO}_{2}$ was found to follow an Arrhenius equation having an activation energy of $49.88 \times 10^{-1}$ $\mathrm{kJ} \mathrm{mol}^{-1}$. Experiments were conducted at 2.5, 5 and $8 \mathrm{ml} \mathrm{h}^{-1} \mathrm{~g}^{-1}$ gas hourly space velocities and it was observed that increasing the hourly gas velocities resulted in a higher $\mathrm{CO}_{2}$ and $\mathrm{CH}_{4}$ conversions while $\mathrm{O}_{2}$ conversion remained fairly constant. $\mathrm{CO}_{2}$ had a high conversion rate of $96 \%$ at $8 \mathrm{ml} \mathrm{h}^{-1} \mathrm{~g}^{-1}$. The synthesized catalytic membrane was characterized by Scanning Electron Microscopy (SEM) and the Energy Dispersive X-ray Analysis (EDXA) respectively. The micrographs showed the Rh particles deposited on the alumina support. Single gas permeation of $\mathrm{CH}_{4}, \mathrm{CO}_{2}$ and $\mathrm{H}_{2}$ through the alumina support showed that the permeance of $\mathrm{H}_{2}$ increased as the pressure was increased to $1 \times 10^{5} \mathrm{~Pa}$. The order of gas permeance was $\mathrm{H}_{2}(2.00 \mathrm{~g} / \mathrm{mol})>$ $\mathrm{CH}_{4}(16.04 \mathrm{~g} / \mathrm{mol})>\mathrm{N}_{2}(28.01 \mathrm{~g} / \mathrm{mol})>\mathrm{O}_{2}(32 \mathrm{~g} / \mathrm{mol})>\mathrm{CO}_{2}(44.00 \mathrm{~g} / \mathrm{mol})$ which is indicative of Knudsen flow mechanism. The novelty of the work lies in the combination of exothermic partial oxidation and endothermic $\mathrm{CO}_{2}$ and steam reforming in a single step in the membrane reactor to achieve near thermoneutrality while simultaneously consuming almost all the greenhouse gases in the feed gas stream.
\end{abstract}

Keywords: Flue Gas, Carbon Dioxide, Methane Hydrogen, Carbon Monoxide, Rhodium Catalyst and Membrane Reactor.

\section{INTRODUCTION}

Major pollutants that come from fossil fuel combustion and industrial processes are methane $\left(\mathrm{CH}_{4}\right)$ and carbon dioxide $\left(\mathrm{CO}_{2}\right)$. Both gases are also major greenhouse gases (GHG) that are thought to be responsible for much of the phenomena leading to global warming [1]. Methane is mostly emitted from uncontrolled degradation of biomasses and inefficient processes of combustion and venting. It is also the main component of natural gas [1]. The development of efficient and economic methane conversion to electricity, fuels and chemicals has become critical in recent years due to the emerging number of untapped unconventional natural gas reserves such as shale gas [2]. There is, therefore, the need to reduce dependence on limited crude oil resources [2-6]. In recent years, industrial routes for one-step conversion of methane to fuels and chemicals are still limited and the most technologically advanced routes involve the indirect conversion of methane (methane steam reforming and partial oxidation) to fuels and chemicals through synthesis gas [7]. These reactions occur at high-temperature and mainly involve the partial or total oxidation of methane to $\mathrm{CO}, \mathrm{H}_{2}$, and $\mathrm{CO}_{2}$ except for the oxidative coupling and non-oxidative conversion of methane that leads to the formation of $\mathrm{C}_{2+}$ hydrocarbons [8-14]. Another important process is the dry reforming of methane which involves the reaction of $\mathrm{CH}_{4}$ with an abundant greenhouse gas $\mathrm{CO}_{2}$ to generate synthesis gas. These two pollutants can then be used together to feed the process of dry reforming and is described by reaction (1) 


$$
\mathrm{CH}_{4}+\mathrm{CO}_{2} \leftrightarrow 2 \mathrm{H}_{2}+2 \mathrm{CO}\left[\Delta \widetilde{\mathrm{H}}_{\text {reaction }}(298 \mathrm{~K})=247.3 \frac{\mathrm{KJ}}{\mathrm{mol}}\right]
$$

This reaction is important for the reduction of emissions and for syngas production. High yield of carbon monoxide and hydrogen can represent the starting point for methanol synthesis [15-17] and ammonia production $[18,19]$ and for Fischer-Tropsch reactions [20, 21].

This reaction is highly endothermic and is catalyzed by transition metals supported on various oxides and the mechanism has been previously studied [22-24]. The rate-limiting step of the process has been shown to be the $\mathrm{C}-\mathrm{H}$ bond activation of methane, which occurs on the transition metal [22]. For the $\mathrm{C}-\mathrm{O}$ bond in $\mathrm{CO}_{2}$, the acidity or basicity of the oxide determines where the activation occurs. For a neutral support, activation occurs on the metal [24].

The problem with dry reforming of methane is the deactivation of the catalyst due to carbon poisoning. It has been suggested that the deactivation of the metal catalyst is more pronounced in the case where metals are supported on neutral supports, as both the $\mathrm{C}-\mathrm{H}$ bond activation in methane and $\mathrm{C}-\mathrm{O}$ bond activation in $\mathrm{CO}_{2}$ are thought to occur on the metal surface. The use of basic supports like $\mathrm{CeO}_{2}$ and $\mathrm{La}_{2} \mathrm{O}_{3}$ has been shown to minimize carbon formation by facilitating dissociation of $\mathrm{CO}_{2}$. This occurs via low-energy barriers through the formation of oxy-carbonates that provide surface oxygen atoms, which facilitate the removal of surface carbon atoms formed during $\mathrm{C}-\mathrm{H}$ bond activation in methane [24]. An additional approach to suppress carbon formation is to synthesize very small metal particles that are well dispersed on the support. A minimum metal particle size is required for the formation of extended carbon structures. Therefore, synthesizing very small, well-dispersed metal particles destabilizes the formation of extended carbon structures and enhances the interaction between the support and the metal, increasing the probability of $\mathrm{O}$ atoms, formed from $\mathrm{CO}_{2}$ dissociation on the support, to oxidize $\mathrm{C}$ atoms on the metal which have been formed from methane dissociation [23]. While there have been many attempts to minimize carbon formation through the routes discussed above, industrial implementation of the process remains challenging.

$\mathrm{Rh}$ catalysts on various supports have been investigated for use in $\mathrm{CH}_{4}$ dissociation, $\mathrm{CO}_{2}$ dissociation, and the dry reforming reaction [25]. The dissociation of $\mathrm{CH}_{4}$ on $\mathrm{Rh}$ was observed at $423 \mathrm{~K}$, producing $\mathrm{H}_{2}$ and small amounts of $\mathrm{C}_{2} \mathrm{H}_{6}$. The intermediate species is undoubtedly $\mathrm{CH}_{3}$, which primarily and rapidly decomposes further to form surface carbon and hydrogen atoms, as no $\mathrm{CH}_{3}$ or $\mathrm{CHx}$ species were identified. For the decomposition of $\mathrm{CH}_{4}, \mathrm{Al}_{2} \mathrm{O}_{3}$ was shown to be the best support for $\mathrm{Rh}$, followed by $\mathrm{TiO}_{2}, \mathrm{MgO}$, and $\mathrm{SiO}_{2}$. The amounts of $\mathrm{C}_{2} \mathrm{H}_{6}$ also decreased in this order. The same study showed that the dissociation of $\mathrm{CO}_{2}$ was aided by the addition of $\mathrm{CH}_{4}$, the hydrogen formed in the $\mathrm{CH}_{4}$ decomposition promotes the dissociation of $\mathrm{CO}_{2}$. Erdohelyi et al. [25] postulated that adsorbed $\mathrm{O}$, which is formed in the decomposition of $\mathrm{CO}_{2}$, facilitates the dissociation of $\mathrm{CH}_{4}$. This contradicts the findings of Rostrup-Nielsen [12], which showed that oxygen atoms only affected $\mathrm{CH}_{4}$ chemisorption and activation by restricting the number of available sites on Ni catalysts and showed that the rate of carbon aging from reactive carbidic carbon to amorphous carbon to graphite increases with increasing temperature. However, no deactivation of the Rh catalysts was found in the dry reforming studies they concluded. This indicates that the formed surface carbon reacted before stable amorphous or graphitic carbon was formed. Furthermore, the ratio of $\mathrm{H}_{2}$ : $\mathrm{CO}$ ratio was found to be greater than one, indicating the presence of secondary processes.

$\mathrm{CO}_{2}$ dissociation depends not only on the type of the catalyst support but also on the gas hourly velocity through the reactor and the rate order on which the reaction will proceed. $\mathrm{CO}_{2}$ chemisorption and dissociation can occur on the surface of a transition or noble metal catalyst and is dominated by electron transfer, which requires the formation of an anionic $\mathrm{CO}_{2}$ precursor [26] as depicted in equations 2 and 3 .

$$
\begin{aligned}
\mathrm{CO}_{2(g)} & \rightleftharpoons \mathrm{CO}_{2(a)} \\
\mathrm{CO}_{2(a)} & \rightleftharpoons \mathrm{CO}_{(a)}+O_{(a)}
\end{aligned}
$$

The adsorbed $\mathrm{O}$ atoms, from the $\mathrm{CO}_{2}$ dissociation, then react with either the methyl radicals or adsorbed $\mathrm{H}$ atoms as shown in equations 4 - 8 .

$$
\begin{aligned}
& \mathrm{CH}_{x(a)}+\boldsymbol{O}_{(a)} \rightarrow \mathrm{CO}_{(a)}+x \mathrm{H}_{(a)} \\
& \mathrm{H}_{(a)}+\boldsymbol{O}_{(a)} \rightleftharpoons \mathrm{OH}_{(a)} \\
& \boldsymbol{H}_{(a)}+\mathrm{OH}_{(a)} \rightleftharpoons \mathrm{H}_{2} \boldsymbol{O}_{(a)}
\end{aligned}
$$




$$
\begin{aligned}
2 H_{(a)} & \rightarrow H_{2(g)} \\
\mathrm{CO}_{(a)} & \rightarrow \mathrm{CO}_{(g)}
\end{aligned}
$$

There is a limit to $\mathrm{CO}$ adsorption because of the availability of the active metal site. This leads to large accumulation of carbon deposits that can gradually lead to catalyst deactivation.

Methane dry reforming mechanism has been widely studied in literature [27-29] and it has been shown that the rate-limiting step in this process is the $\mathrm{C}-\mathrm{H}$ bond activation in methane which occurs on the transition metal [27]. For the $\mathrm{C}-\mathrm{O}$ bond in $\mathrm{CO}_{2}$, the acidity or basicity of the oxide determines where the activation occurs. For a neutral support, activation occurs on the metal [30]. Another challenging factor with dry reforming of methane is the deactivation of the catalyst due to carbon poisoning. It has been suggested that the deactivation of the metal catalyst is more pronounced in the case where metals are supported on neutral supports since both the $\mathrm{C}-\mathrm{H}$ bond activation in methane and $\mathrm{C}-\mathrm{O}$ bond activation in $\mathrm{CO}_{2}$ occur on the metal surface. The use of basic supports like $\mathrm{CeO}_{2}$ and $\mathrm{La}_{2} \mathrm{O}_{3}$, has been shown to minimize carbon formation by facilitating dissociation of $\mathrm{CO}_{2}$ with low energy barriers through the formation of oxy-carbonates, and providing surface oxygen atoms for facilitating the removal of the surface carbon atoms formed during $\mathrm{C}-\mathrm{H}$ bond activation in methane $[24,26]$. Noble metals, on the other hand, are generally more expensive but have an increased resistance to coking in comparison to transition metals. In a previous work, nickel was used as a substitute for the noble metals, but it was prone to coking as carbon can dissolve in the Ni layer [30].

The use of a catalytic membrane reactor (CMR) can be advantageous for methane reforming reactions as some of the functions of the CMR cannot be performed by the traditional packed bed reactor (PBR). A characteristic feature of CMRs is that the reaction and separation can be carried out simultaneously in the same system, hence, increasing the product yield by selectively removing the products. Recent studies have addressed new concepts like general correlations of reactor performance [28], and the role of primary and secondary reaction products [29]. The use of CMRs for steam or dry reforming reactions requires membranes that can withstand the high temperatures and pressures that are used in these reactions. The membrane used in this work is a porous $y$-alumina tubular support which provides a robust structure for creating a catalytic coating with rhodium metal that can promote chemical transformations with the catalyst incorporated into the pores of the support. The goal is to develop a catalytic membrane reactor process where the $\mathrm{CO}_{2}$ in flue gas is rehabilitated into value-added chemical products. The reactor is fed with a mixture of the flue exhaust gases consisting mostly of carbon dioxide $\left(\mathrm{CO}_{2}\right)$, oxygen $\left(\mathrm{O}_{2}\right)$ and nitrogen $\left(\mathrm{N}_{2}\right)$. With the deliberate inclusion of $\mathrm{CH}_{4}$, and at elevated temperatures, the highly dispersed Rh catalyst facilitates the breakdown of the $\mathrm{CH}_{4}$ and $\mathrm{CO}_{2}$ and then reconstitutes the resulting mixture using the $\mathrm{O}_{2}$ already present in the flue gas to form a mixture of $\mathrm{CO}$ and $\mathrm{H}_{2}$ which is diluted in the nitrogen stream. The $\mathrm{CO}$ and $\mathrm{H}_{2}$ mixture called "syngas" or "synthesis gas" is the backbone of the heavy chemicals and petrochemicals industry and is used for the manufacture of highly useful chemical constituents such as Fischer-Tropsch fuels, hydrogen and ammonia/urea. The nitrogen stream also offers an opportunity to produce bulk nitrogen for the commercial merchant industrial gas market. Rhodium catalyst have been deposited on an alumina porous tubular support using rhodium (III) chloride precursor and incorporated into a shell and tube membrane reactor to measure conversion yield of $\mathrm{CH}_{4}$ and $\mathrm{CO}_{2}$. The main assumption in this work is that the reaction of feed gases produces a mixture consisting of $\mathrm{CO}$, $\mathrm{O}_{2}, \mathrm{H}_{2}, \mathrm{H}_{2} \mathrm{O}$ and solid carbon (C). This study represents the kinetics of methane dry reforming using $\mathrm{CO}_{2}$ and determines the order of reaction as well as the conversion rates using three different weight hourly space velocities.

\subsection{Theory}

For various reactions, at a given temperature, the reaction rate can be expressed as a product of the reaction rate constant and the concentration of the reacting species raised to the power of the order of reaction:

$r_{\mathrm{CO}_{2}}=\boldsymbol{k} \boldsymbol{C}_{\mathrm{CO}_{2}}{ }^{\eta}$

Where $\boldsymbol{r}_{\mathrm{CO}_{2}}$ is the rate of reaction, $\mathrm{C}_{\mathrm{CO}_{2}}$ is the concentration of $\mathrm{CO}_{2}$ in the reaction, $k$ is the reaction rate constant and $\eta$ is the order of the reaction.

For a differential reactor under plug flow operating conditions $\boldsymbol{r}_{\mathrm{Co}_{2}}$ is given by the equation:

$r_{\mathrm{Co}_{2}}={ }^{X_{\mathrm{CO}_{2}}} /\left(W / \mathrm{F}_{\mathrm{CO}_{2}}\right)$ 
Where $\boldsymbol{W}$ is the weight of the catalyst used in the reaction and $\boldsymbol{F}_{\mathrm{CO} 2}$ is the feed flow rate of carbon dioxide into the reactor.

Combining equation (9) and (10) gives equation (11):

$\frac{X_{C O_{2}}}{{ }^{W} / \mathrm{F}_{C O_{2}}}=\boldsymbol{k} C_{C O_{2}}{ }^{\eta}$

Rearranging equation (11) gives equation (12):

$\ln \frac{X_{\mathrm{CO}_{2}}}{\mathrm{~W}_{\mathrm{F} \mathrm{Fo}_{2}}}=\ln k+\eta \ln C_{\mathrm{CO}_{2}}$

For a first order reaction, a plot of $\ln \frac{x_{\mathrm{CO}_{2}}}{W_{/ \mathrm{FO}_{2}}}$ against $\ln C_{\mathrm{CO}_{2}}$ is expected to give a straight-line graph with a slope of 1 if the reaction is first order in $\mathrm{CO}_{2}$. The activation energies of the reacting species were determined using the Arrhenius equation (13):

$k_{i}=k_{o} e^{-E_{i} / R T}$

Rearranging equation (13) gives equation (14)

$\ln k_{i}=\ln k_{o}-\frac{E_{i}}{R T}$

Where $\boldsymbol{k}_{i}$ is the reaction rate constant, $\boldsymbol{k}_{\boldsymbol{o}}$ the pre-exponential factor, $\boldsymbol{R}$ the ideal gas constant, $\boldsymbol{T}$ the absolute reaction temperature and $\boldsymbol{E}_{i}$ the activation energy of reacting species $i$. A plot of Inki against $1 / T$ should yield a straight line with an intercept of In $\boldsymbol{k}_{o}$ and a slope of $-E_{i} / \boldsymbol{R}$.

Thermodynamically, in order to produce synthesis gas with $\mathrm{H}_{2} / \mathrm{CO}$ ratio of 2 , the energy requirement for the three processes (dry reforming of methane, steam reforming of methane and partial oxidation of methane) involved in the flue gas reforming must be calculated. This calculation shows that if the amount of energy consumed by absorption is taken into account (as it is supplied as a reactant to produce synthesis gas with the desired ratio) then it can be estimated that to produce one mole of hydrogen and two moles of carbon monoxide, 0.233 mol $\mathrm{CH}_{4}$ is consumed and produces 0.013 mole $\mathrm{CO}_{2}$ emission per $\left(\mathrm{CO}+2 \mathrm{H}_{2}\right)$ in modern flue gas reformation (oxy$\mathrm{CO}_{2}$-steam reforming) which is far lower than either the $\mathrm{CO}_{2}$ dry reforming or steam methane reforming [22-27]. The presence of $\mathrm{H}_{2} \mathrm{O}$ provides a source for surface oxygen and hydroxyl-radicals, $\mathrm{O}(\mathrm{s})$ and $\mathrm{OH}(\mathrm{s})$, which in turn can result in very high methane conversion, higher $\mathrm{H}_{2}$ and lower $\mathrm{CO}$ selectivity. This is highly desirable for catalytic membrane reactors as hydrogen can aid the stabilization of the post-catalyst gaseous combustion zone located in the bore of the membrane tube.

\section{MATERIAL AND METHODS}

\subsection{Membrane Preparation on y-alumina Support}

Electroless plating deposition of the rhodium was carried out using as rhodium chloride supplied by SigmaAldrich on a $6000 \mathrm{~nm}$ pore size commercially available $y$-alumina support that has a porosity of $45 \%$ and was supplied by ceramiques techniques et industrielles (CTI SA), France. This was achieved by dissolving $10 \mathrm{~g}$ of $98 \% \mathrm{RhCl}_{3}$ in $500 \mathrm{~mL}$ of deionized water and left to stir for $24 \mathrm{~h}$. The $6,000 \mathrm{~nm}$ pore size $\mathrm{y}$-alumina support was soaked in deionized water for $2 \mathrm{~h}$ and then dipped into the $\mathrm{RhCl}_{3}$ solution and left for $20 \mathrm{~h}$. Catalytic reduction of the $\mathrm{RhCl}_{3}$ and activation of the rhodium metal on the membrane was carried out by passing hydrogen gas through the membrane in the membrane reactor at $573 \mathrm{~K}$ for $30 \mathrm{~min}$. The catalyst loading was determined by equation (15).

catalyst loading $(\%)=\frac{W_{R h}-W_{A l}}{W_{R h}} X 100$

Where $W_{A l}$ is the weight of the membrane before impregnation with $\mathrm{Rh}(\mathrm{g})$ and $\boldsymbol{W}_{R \boldsymbol{h}}$ is the weight of the membrane after Rh deposition (g).

\subsection{Membrane Characterisation}


A Zeiss Evo LS10 Scanning Electron Microscope (SEM) with an Oxford Instruments INCA System Energy Dispersive X-Ray analyser (EDAX) (Zeiss, United Kingdom) was used to determine the morphology and elemental composition of the prepared membrane. The sample was prepared on a stub and a suspension of silver from Agar Scientific was added allowed to dry for $24 \mathrm{~h}$ prior to obtaining SEM images. Operating parameters for both the SEM and EDAX are provided in Table 1.

Table 1: SEM and EDAX operating parameters

\begin{tabular}{lll}
\hline Parameters & EM & EDAX \\
\hline Working distance $(\mathrm{mm})$ & 8.5 & 8.5 \\
Gun beam $(\mathrm{pA})$ & 1 & 10 \\
Magnification $(\mathrm{x})$ & any & 200 \\
\hline
\end{tabular}

\subsection{Gas Permeation Tests}

Gas permeation experiments were conducted using the method adapted from Gobina [33] (GOBINA, E. 2006). The schematic diagram of the experimental flow apparatus dedicated to the measurement of the gas permeation is shown in Fig 1 . The apparatus, which is constructed by using standard UHV stainless steel components, is comprised of three main sections: feed gas delivery, membrane-holder and the permeate flow measurement. The membrane-holder consists of a stainless-steel tube (Length of membrane $(L)=395$ $\mathrm{mm}$, outer diameter (O.D) $=36 \mathrm{~mm}$, inner diameter (I.D) $=28 \mathrm{~mm}$ and thickness $(\mathrm{t})=1.3$ $\mathrm{mm}$ ) with threaded end-fittings at both ends to accommodate the 'O' ring high-temperature seals and threaded end-caps plugs which when screwed onto the steel tube threaded ends compresses the seals thus creating the seal that separates the shell-side from the tube-side, this centralizes the membrane to enable flow through the membrane from the shell-side into the tube-side [33]. The outside surface of the stainless-steel tube is enclosed by an electric heating jacket and has three type $\mathrm{K}$ thermocouples strategically located at the top, middle and bottom of the stainless-steel shell to monitor and record the temperature. The pure gases from the high-pressure cylinder are fed through a gas inlet line that is constructed with copper pipes $(6 \mathrm{~mm}$ external diameter) to the shell-side of the membrane-holder through a variable valve. The pressure in the gas inlet gas line during measurements is monitored using a digital pressure gauge which is located between the valve and the shell-side sample holder inlet. A digital flow meter with full scale reading of 10 standard liters per minute (L/min) $\mathrm{H}_{2}$ and $0.01 \%$ full-scale (FS) resolution is positioned between the tube-side exit of the membrane reactor. With one of the tube-side inlets closed and one of the shell-side exits closed, the feed gas is directed to permeate into the bore of the support tube and in co-current configuration directed into the flow meter where the flow rate is displayed and recorded at atmospheric pressure. The experiments are repeated three times and an average value calculated. The permeance was determined by the following equation:

$J=\frac{F}{A \Delta P}$

Where $J$ is the permeance $\left(\mathrm{mol} \cdot \mathrm{m}^{-2} \cdot \mathrm{s}^{-1} \cdot \mathrm{Pa}^{-1}\right), F$ is the volumetric flow rate (mol.s $\left.\mathrm{s}^{-1}\right), A$ is the surface area of the membrane $\left(\mathrm{m}^{2}\right)$ and $\Delta P$ is the pressure difference across the membrane.

The separation factor of two pure gases across a membrane is given by the ratio of the individual gas permeances as described in equation 17 :

$\propto_{a / b}=\frac{J_{a}}{J_{b}}=\frac{F_{a}}{F_{b}}$

Where $\alpha_{a / b}$ is the separation factor of gas a to gas $b, J_{a} \& J_{b}$ are the permeances and $F_{a}$ and $F_{b}$ are the flow rates.

The Knudsen selectivity of gas a over gas $b$ is given by the reciprocal of the square root of the ratio of their respective molecular weights as shown in equation 18.

$\propto_{a / b(\text { Knudsen })}=\left(M_{b} / M_{a}\right)^{0.5}$ 
Where $\alpha_{a / b}$ (Knudsen) is the Knudsen selectivity of gas a over gas b, $M_{a}$ and $M_{b}$ are the molecular weights of gas $a$ and gas $b$ respectively.

\subsection{Reaction Tests and GC-MS Analysis}

The experimental rig (Fig. 1) was reconfigured to include the gas chromatograph, heating furnace and temperature controller in order to carry out the reaction tests and analysis of the feet and reaction products. It and consists of a membrane reactor enclosed in a furnace that is operated at high temperature using a power regulator (Horst, Germany). The feed and permeate streams were connected separately to the online GC-MS. The inlet gas comprised of synthetic off-gas mixture containing $4.5 \% \mathrm{O}_{2}, 2.5 \% \mathrm{CH}_{4}, 12.5 \% \mathrm{CO}_{2}$, and balance nitrogen (+/- $2 \%$ uncertainty) supplied by BOC, Aberdeen, Scotland. Prior to the reaction tests the membrane catalyst stability was tested using the flue gas mixture for up to three hours to confirm that stable operation has been achieved. The kinetic reaction tests were carried at atmospheric pressure and a temperature range of 973 to $1173 \mathrm{~K}$ using pre-mixed feed gases and the product stream were sent to the online GC (Agilent Technologies, Santa Clara, California, USA) equipped with a mass spectrometry detector (MS) for analysis using an automated 6-port gas sampling valve (Agilent Technologies, Santa Clara, USA) on a $30 \mathrm{~mm}$ Plot $\mathrm{H}$ column and a Varian gas chromatograph equipped with three automated gas sampling valves - Valco Instruments, Houston, Texas, USA).

A typical kinetic experimental procedure involved weighing and inserting the catalytic membrane in the reactor side. High-temperature seals were positioned at both ends of the reactor with the fittings and the end screw caps were tightened. A leak test was then carried out by pressurizing the shell-side (tube side also was pressurized for membrane permeation experiments) and ensuring that the pressure gauge reading was constant and did not show any pressure drop over a $2 \mathrm{~h}$ period. The membrane reactor was heated to the temperature of $723 \mathrm{~K}$ by adjusting the controls on the power supply unit with continuous flow of argon ( 28 $\left.\mu \mathrm{mol} \mathrm{s}{ }^{-1}\right)$ and the $\mathrm{RhCl}_{3}$ coated membrane was reduced to Rh membrane in hydrogen $\left(\sim 24 \mu \mathrm{mol} \mathrm{s} \mathrm{s}^{-1}\right)$ for a period of 30 mins, and then heated to the reaction temperature with only the Ar flow. The synthetic flue gas feed mixture consisting of $\mathrm{CH}_{4}(2.5 \%), \mathrm{CO}_{2}(12.5 \%)$ and $\mathrm{O}_{2}(4.4 \%)$ with balance nitrogen was introduced to the shell-side inlet with the other inlet closed so that the mixture was forced to travel through the pores of the membrane which contained the catalysts into the bore of the membrane tube (to obtain flow rate in $\mathrm{cm}^{3}$ (NTP) min-1, multiply flow in units of $\mu \mathrm{mol} \mathrm{s} \mathrm{s}^{-1}$ by 1.5). The gases exiting the membrane reactor system mainly contains generated gas $\left(\mathrm{H}_{2}\right.$ and $\left.\mathrm{CO}\right)$, unreacted gases $\left(\mathrm{CH}_{4}, \mathrm{O}_{2}\right.$, and $\left.\mathrm{CO}_{2}\right)$ and inert gas $\left(\mathrm{N}_{2}\right)$. These gases are sent to the online GC shown in (Agilent Technologies, Santa Clara, California, USA) equipped with a mass spectrometry detector (MS) for analysis equipped with an automated 6-port gas sampling valve (Agilent Technologies, Santa Clara, USA) and a Varian gas chromatograph equipped with three automated gas sampling valves - Valco Instruments, Houston, Texas, USA). The gas automated gas samplers enable introduction of a fixed quantity of gas samples through an automated operation, at ambient temperature conditions. The sample volume can be selected in 1,2 , or $5 \mathrm{ml}$ by adjusting the valve operation. In our work a $1 \mathrm{ml}$ loop was operated throughout the experiments reported. Hayesep Q 80-100 MESH packed SS column $(2 \mathrm{~m} \times 1 / 8$ " $\times 2.0 \mathrm{~mm})$, and 2 SS columns each packed with Molecular sieve $60-80 \mathrm{MESH}\left(2 \mathrm{~m} \times 1 / 8^{\prime \prime} \times 2 \mathrm{~mm}\right)$ were used for gas separation. For the Varian GC, the temperature of the injector port, column temperature, and TCD temperature were all maintained at $423 \mathrm{~K}$ with a TCD current of $60 \mathrm{~mA}$. Helium is used as a carrier gas for GC for the detection of all the gases exiting the reactor. The exit gas sample was injected every 15-30 mins until a steady state was attained which was indicated by a constancy of the chromatogram areas for all the components being sampled. The stream was analysed periodically until both the $\mathrm{CO}_{2}$ and $\mathrm{CH}_{4} \mathrm{Conversions}$ indicated the attainment of steady-state values. The procedure was then repeated for the other temperatures studied. 


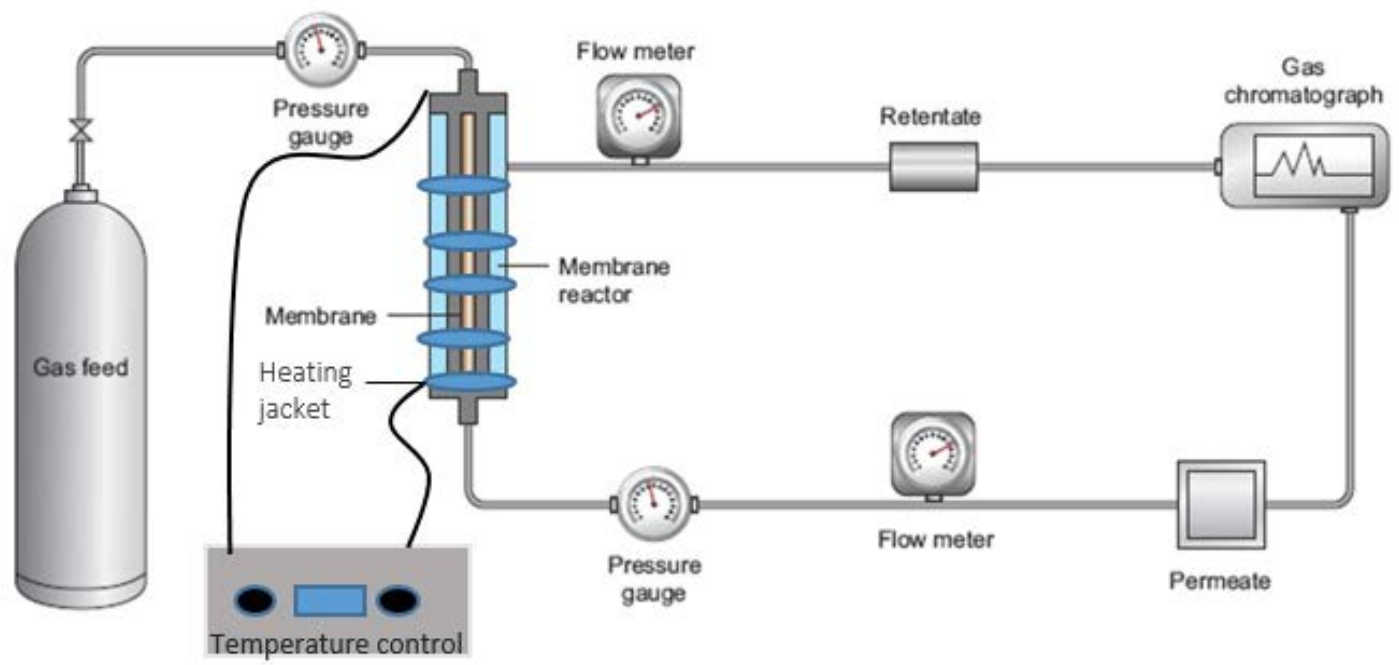

Fig. 1: Experimental rig setup

\section{RESULTS AND DISCUSSION}

\subsection{Reaction Kinetics Tests}

To determine the reaction order, a plot of $\ln \frac{x_{A}}{W / F_{A O}}$ against $\ln C_{\mathrm{CO}_{2}}$ was used to obtain the reaction order as shown in Fig.2. It can be observed that the reaction obeyed first-order for $\mathrm{CO}_{2}$, for this reaction the dilution ratio of $\mathrm{CO}_{2}: \mathrm{N}_{2}$ was kept at 1:6. The graph has a slope of 1.00 and a correlation coefficient value of 1.00. The determined reaction rate of $\mathrm{CO}_{2}$ reforming of methane over $\mathrm{Rh} / \mathrm{Al}_{2} \mathrm{O}_{3}$ is therefore determined to be a first-order reaction.

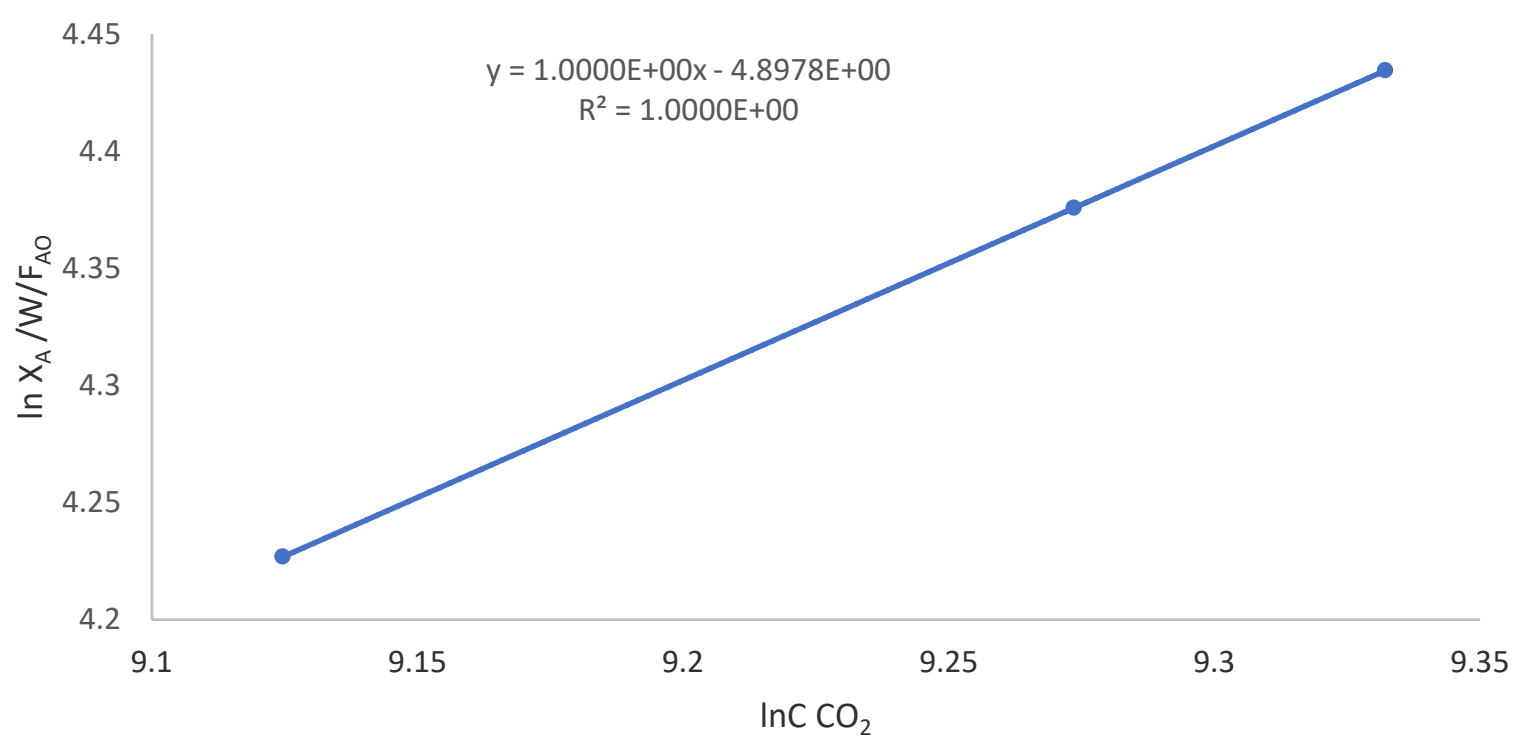

Fig. 2: Test for first-order reaction kinetics of $\mathrm{CO}_{2}$ reforming of methane over $\mathrm{Rh} / \mathrm{AlO}_{3}$ catalyst

Using equation (10) for $\mathrm{CO}_{2}$, and written for $\mathrm{CH}_{4}$ and $\mathrm{O}_{2}$ and the Arrhenius equation (14) the activation energies and pre-exponential constants of $\mathrm{CO}_{2}, \mathrm{CH}_{4}$ and $\mathrm{O}_{2}$ were determined and the results are presented in Table 2 . The activation energy was determined using the temperatures of 973,1073 and $1173 \mathrm{~K}$. $\mathrm{CO}_{2}$ is expected to have higher activation energy than that $\mathrm{CH}_{4}$. This implies that $\mathrm{CO}_{2}$ is more difficult to convert than $\mathrm{CH}_{4}$. The activation energy of $\mathrm{O}_{2}$ was found to be close to that of $\mathrm{CO}_{2}$ but the conversion of $\mathrm{CO}_{2}$ and $\mathrm{O}_{2}$ was found to be higher 
than that of $\mathrm{CH}_{4}$. However, our activation energy values were found to be an order of magnitude lower than those of similar studies carried out using rhodium catalysts with traditional reactors. The activation energy is the minimum (least possible) amount of energy which is required to initiate a chemical reaction or the amount of available energy in a chemical system for reaction to take place. Our reactor is untraditional in that the rhodium catalysts are attached on the pores of the porous alumina tubular support as highly dispersed nano particles with the feed stream forced to flow right through the membrane thickness. This means that the entire catalytic surface is being utilized, and all the reactants have contact with the active catalytic sites. Moreover, such a configuration means that the carbon monoxide is not allowed sufficient time to further react with more oxygen to produce carbon dioxide. As a result of these factors the energy required to initiate the reaction is greatly reduced which significantly reduces the activation energy values.

Table 2: Activation energies determined between 973 to $1173 \mathrm{~K}$ using the Arrhenius equation

\begin{tabular}{lll}
\hline Reactants & $\boldsymbol{k}_{\boldsymbol{o}}$ & $\boldsymbol{E}, \mathrm{kJ} / \mathrm{mol}$ \\
\hline $\mathrm{CO}_{2}$ & $1.63 \mathrm{E}-4$ & $49.88 \mathrm{E}-1$ \\
$\mathrm{CH}_{4}$ & 443.60 & $16.63 \mathrm{E}-1$ \\
$\mathrm{O}_{2}$ & 511.11 & $41.57 \mathrm{E}-1$ \\
\hline
\end{tabular}

\subsection{Membrane Characterization}

Morphological studies of the synthesised rhodium membrane confirmed that the Rhodium particles were deposited on the alumina support and were embedded within the pores. Fig 3 (a) shows the $y$-alumina support and Fig 3 (b) shows the synthesized rhodium membrane after calcination in hydrogen flow. A summary of the elemental composition in Table 3 shows the presence of Rh on the $\mathrm{Y}$-alumina support which is absent in the fresh support. This confirms the attachment of rhodium in the pores of the support matrix. 

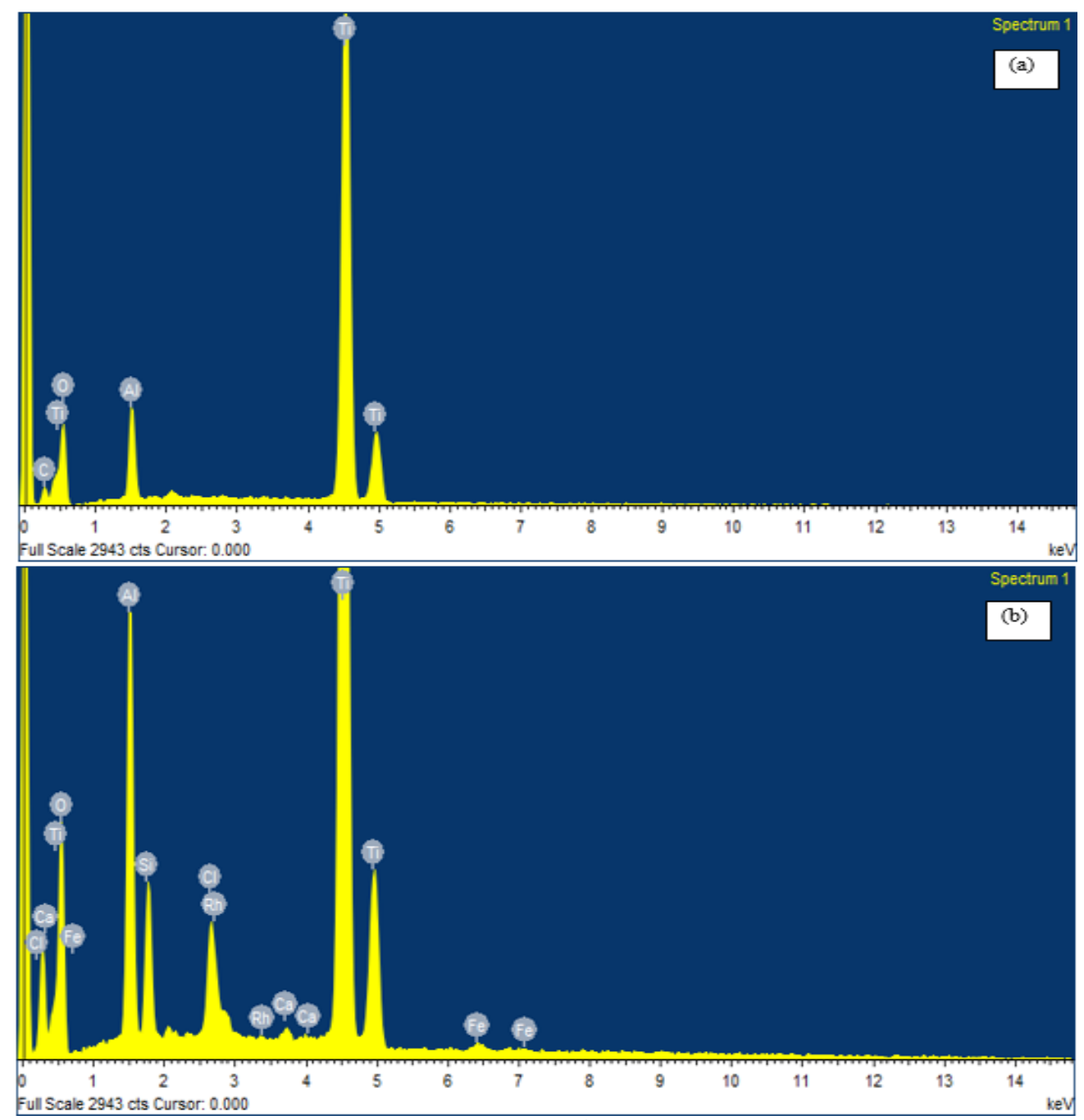

Fig. 3: EDAX for (a) $y$-alumina support and (b) $R h / \gamma$-alumina membrane.

Table 3: Elemental composition of $\mathrm{\gamma}$-alumina and $\mathrm{Rh} / \mathrm{\gamma}$-alumina membrane

\begin{tabular}{|c|c|c|}
\hline Elements & $\begin{array}{l}\text { \%weight composition } \\
\text { (y-alumina support) }\end{array}$ & $\begin{array}{l}\text { \%weight composition } \\
\text { (Rh/Y-alumina } \\
\text { membrane) }\end{array}$ \\
\hline $\mathrm{O}$ & 7.29 & 20.5 \\
\hline $\mathrm{Al}$ & 0.82 & 3.82 \\
\hline $\mathrm{Si}$ & & 1.43 \\
\hline $\mathrm{Cl}$ & & 0.97 \\
\hline $\mathrm{Ca}$ & & 0.14 \\
\hline $\mathrm{Ti}$ & 9.68 & 23.63 \\
\hline $\mathrm{Fe}$ & & 0.23 \\
\hline $\mathrm{Rh}$ & & 0.94 \\
\hline $\mathrm{C}$ & 0.79 & \\
\hline
\end{tabular}


The EDAX elemental analysis showed the amount of Rh catalyst on the support to be $0.94 \%$. Moreover, the catalyst loading on the $\gamma$-alumina support is $0.52 \%$. SEM images of the $\gamma$-alumina membrane and the rhodium impregnated $\gamma$-alumina membrane are presented in Figs 4 and 5.

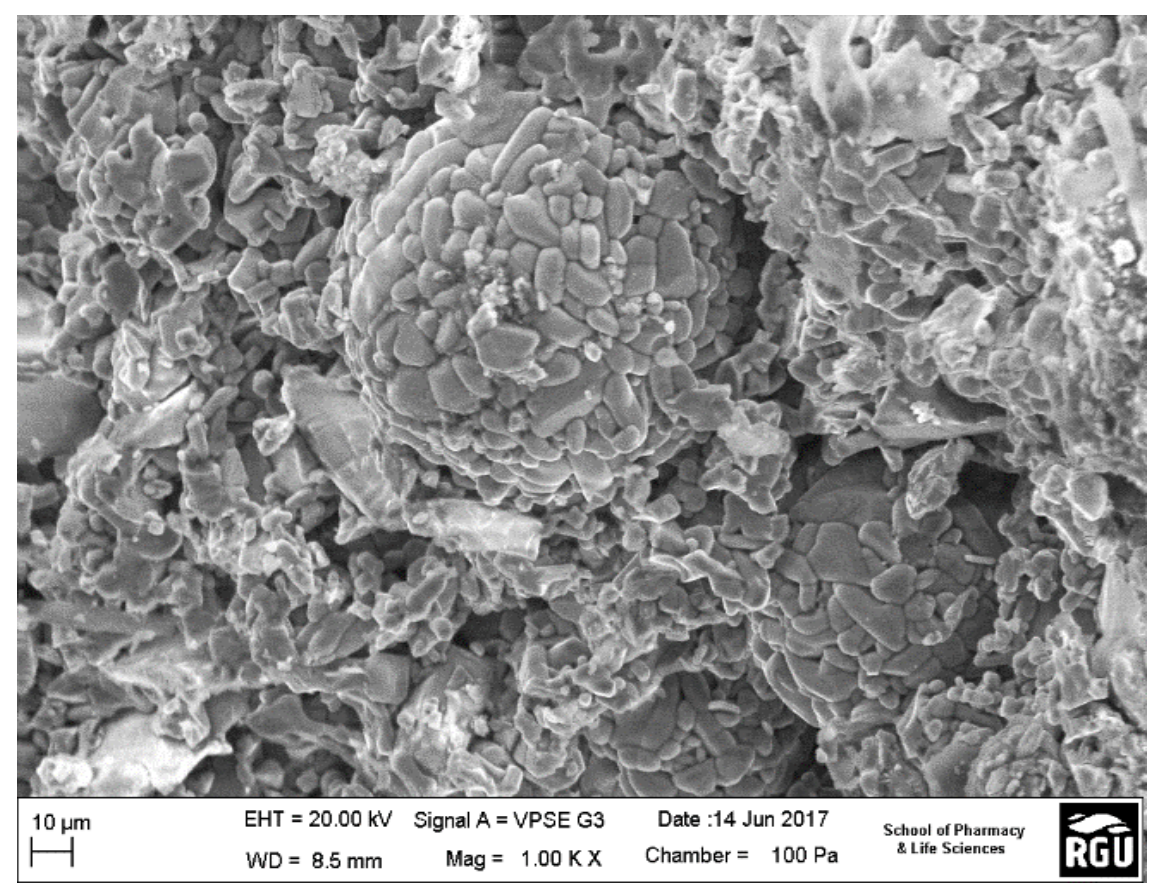

Fig. 4: $y$-alumina membrane.

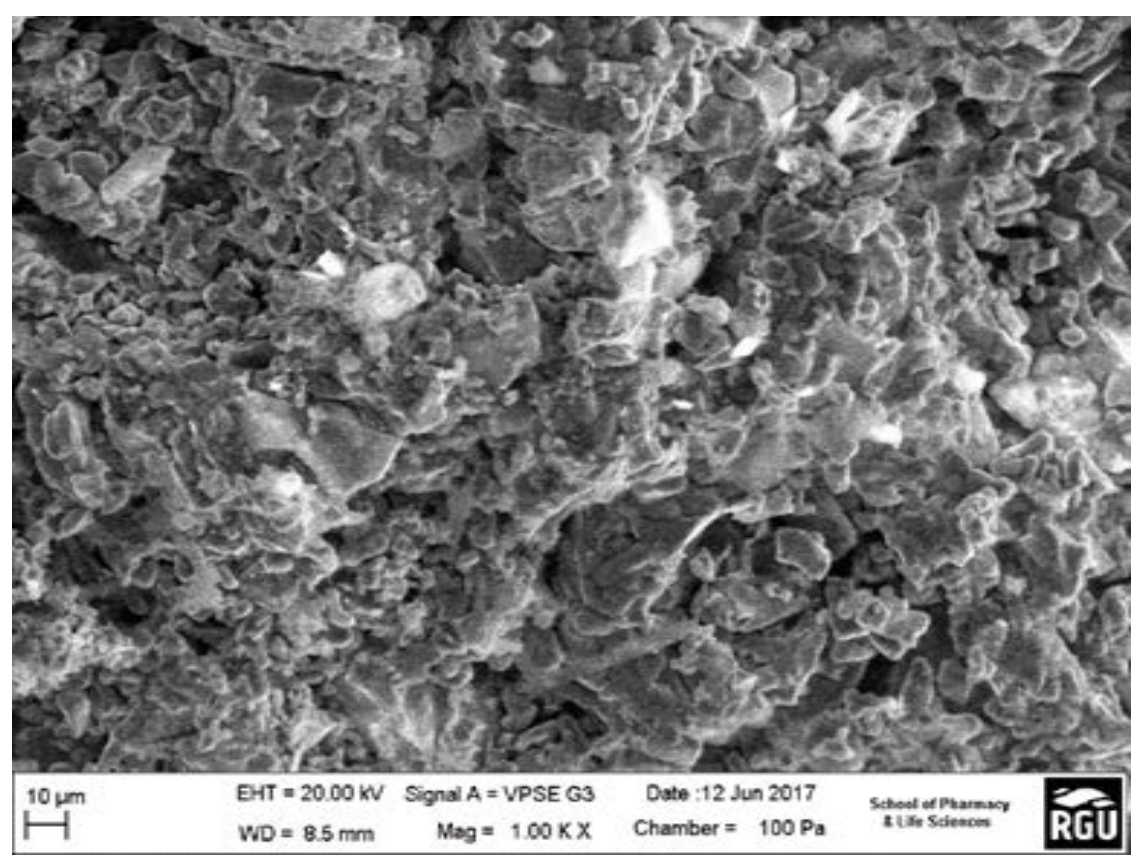

Fig. 5: Rh/Y-alumina membrane.

\subsection{Permeation tests using alumina support}

Single gas permeation of $\mathrm{CH}_{4}, \mathrm{CO}_{2}, \mathrm{~N}_{2}$ and $\mathrm{H}_{2}$ through the $\gamma$-alumina support is presented in Fig 6 . The permeance of $\mathrm{H}_{2}$ was shown to decrease as the pressure was increased to $1.2 \times 10^{5} \mathrm{~Pa}$. The order of gas 
permeance through the membrane was $\mathrm{H}_{2}(2.00 \mathrm{~g} / \mathrm{mol})>\mathrm{CH}_{4}(16.04 \mathrm{~g} / \mathrm{mol})>\mathrm{N}_{2}(28.01 \mathrm{~g} / \mathrm{mol})>\mathrm{O}_{2}(32 \mathrm{~g} / \mathrm{mol})$ $>\mathrm{CO}_{2}(44.00 \mathrm{~g} / \mathrm{mol})$. Therefore, the flow mechanism was based on the relative molecular masses of the gases. This is indicative of Knudsen flow mechanism.

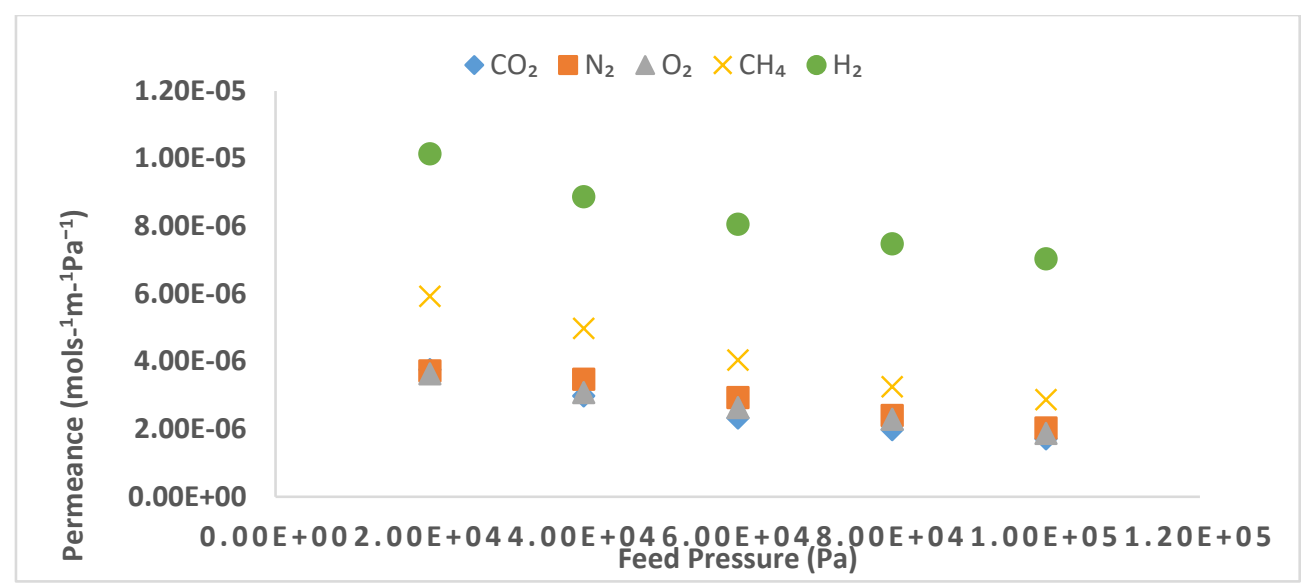

Figure 6: Gas permeance through the $\mathrm{V}$-alumina support at $673 \mathrm{~K}$

Fig 7 shows hydrogen selectivity through the $y$-alumina support determined using equation 17 . The selectivity was found to increase with increased gas feed pressures. Consequently, there is not much segregation of the feed gas stream constituents in the membrane due to Knudsen diffusion. However, after the chemical reaction takes place, the produced $\mathrm{H}_{2}$ transported at a higher rate away from the reaction zone due to Knudsen separation of $\mathrm{H}_{2}$. This enhances the conversion of $\mathrm{CO}_{2}, \mathrm{O}_{2}$ and $\mathrm{CH}_{4}$ as a result of equilibrium-shift and thus increases the yield of syngas [34]. This is one of the advantages of our membrane reactor process over a conventional packed bed reactor (PBR). In PBRs there is significant mass transfer limitations due to gas phase transfer within the pellets and also product transfer from pellets to gas phase. Patil et al. [32] have previously carried out methane reforming reactions with a noble metal catalyst at $823 \mathrm{~K}$ at $2 \times 10^{5} \mathrm{~Pa}$ in a CMR. This consisted of a palladium-based membrane. Moreover, conversion enhancements of $27 \%-53 \%$ were achieved. Tong and Matsumura [31] also investigated methane reforming reactions with a CMR. They used a commercial nickel catalyst at $773 \mathrm{~K}$ and $823 \mathrm{~K}$ and obtained hydrogen permeances of $1-3 \times 10^{-6} \mathrm{~mol} \mathrm{~m}^{-2} \mathrm{~s}^{-1}$ $\mathrm{Pa}^{-1}$. In this work, hydrogen permeances of $2.4-3.9 \times 10^{-6} \mathrm{~mol} \mathrm{~m}^{-2} \mathrm{~s}^{-1} \mathrm{~Pa}^{-1}$ have been achieved. These are found to be within the range of those reported in the literature [29].

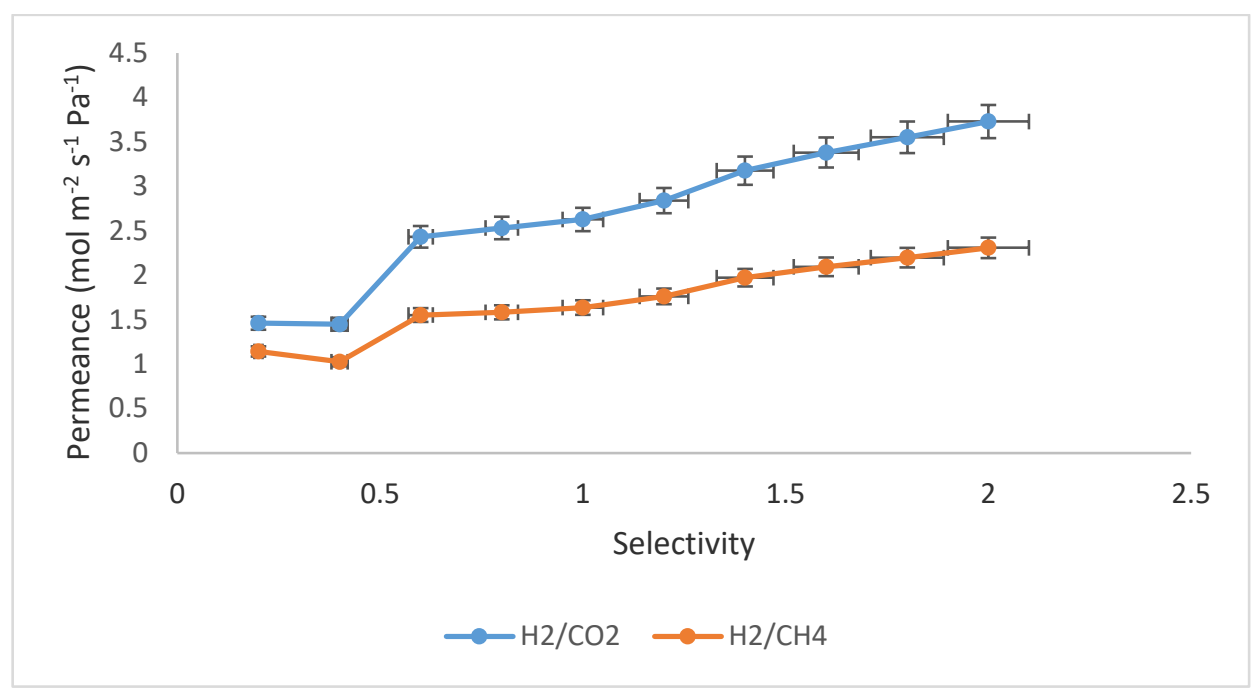

Fig. 7: Selectivity of the $\gamma$-alumina support at $673 K$ to hydrogen. 
A comparison of experimental $\mathrm{H}_{2}$ separation factors obtained from individual gas permeances (at $\mathrm{T}=293$ $673 \mathrm{~K}$ ) as well as the theoretical Knudsen values are shown in Table 4. The experimental separation factors obtained with the porous $y$-alumina support were close to that predicted using the inverse square root of molecular weight relationship given by the Knudsen equation and the temperature dependency for diffusion was found to be roughly dependent on $\mathrm{T}^{-0.55}$. This good match between the theoretical and experimental results indicates very strongly that the mode of transport of all species through the support was molecular. It was not possible for health and safety reasons to carryout pure hydrogen permeation tests above $673 \mathrm{~K}$.

Table 4: Comparism of Knudsen and experimental selectivity for porous $Y$-alumina support at $T=293-673 \mathrm{~K}$ and $\triangle \mathrm{P}=2 \times 10^{5} \mathrm{~Pa}$.

\begin{tabular}{lll}
\hline Ratio & Theoretical (Knudsen value) & Experimental value \\
\hline $\mathrm{H}_{2} / \mathrm{CH}_{4}$ & 2.83 & 2.31 \\
$\mathrm{H}_{2} / \mathrm{N}_{2}$ & 3.74 & 3.14 \\
$\mathrm{H}_{2} / \mathrm{O}_{2}$ & 4.00 & 3.39 \\
$\mathrm{H}_{2} / \mathrm{CO}_{2}$ & 4.69 & 3.73 \\
\hline
\end{tabular}

\subsection{Conversion Analysis}

A graph of the conversion of $\mathrm{CO}_{2}, \mathrm{CH}_{4}$ and $\mathrm{O}_{2}$ as a function of the inlet space hourly velocity is presented in Figure 6. At different gas space hourly velocities, there is a constant $100 \%$ conversion for $\mathrm{O}_{2}$. For the greenhouse gases $\left(\mathrm{CO}_{2}\right.$ and $\left.\mathrm{CH}_{4}\right), \mathrm{CO}_{2}$ had the highest conversion at a velocity of $8.3 \mathrm{ml} \mathrm{h}^{-1} \mathrm{~g}^{-1}$. In general, however, the conversion increased with an increase in space hourly velocity for $\mathrm{CH}_{4}$ and $\mathrm{CO}_{2}$.

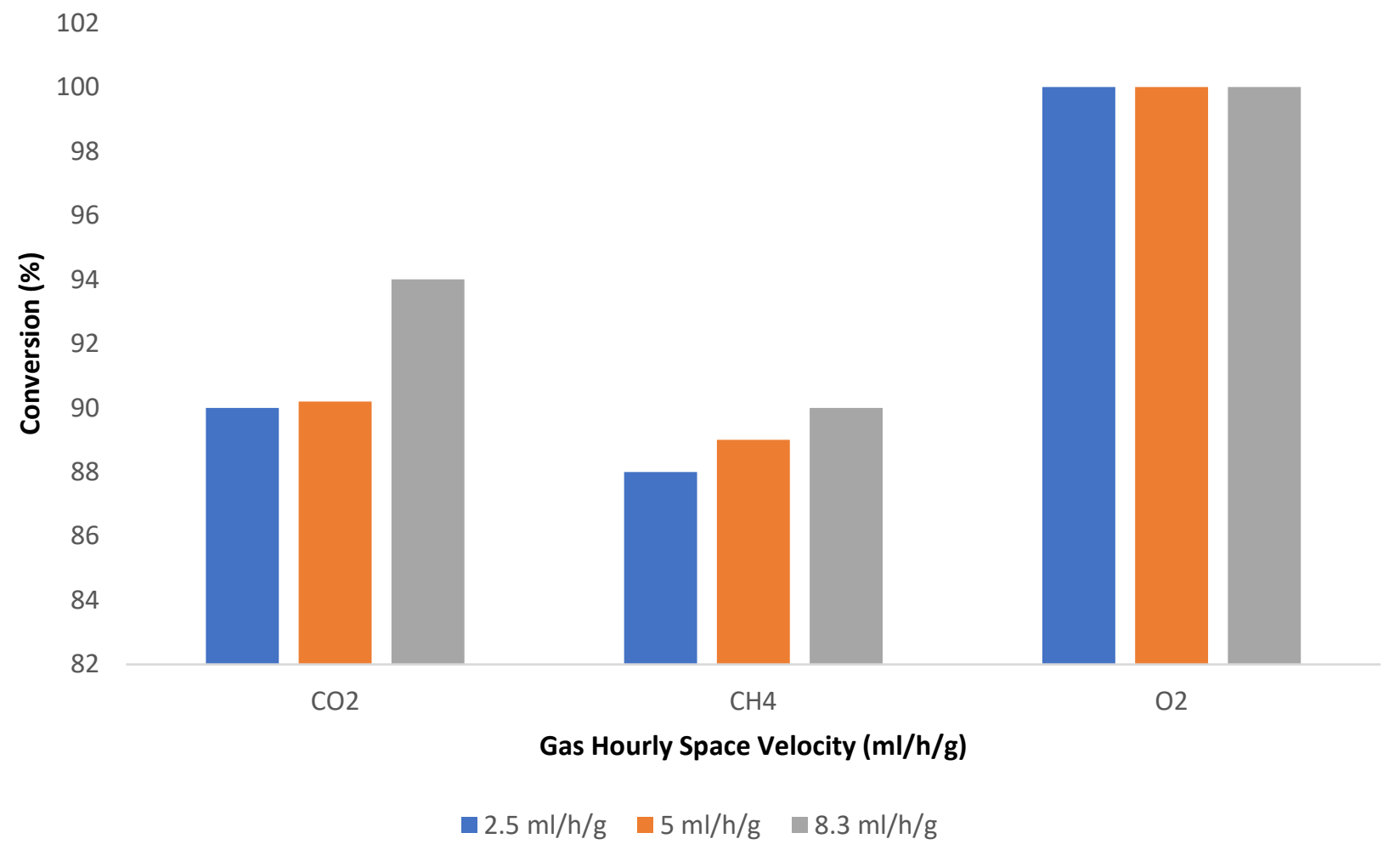

Fig. 8: Conversion rates for $\mathrm{CO}_{2}, \mathrm{CH}_{4}$ and $\mathrm{O}_{2}$ at different gas hourly space velocities. 


\section{CONCLUSIONS}

In this work, a new catalytic configuration incorporating a catalytic membrane process has been tested having controlled surface species embedded into porous networks responsible for the catalytic reaction. The flue gas $\left(\mathrm{CO}_{2}+\mathrm{H}_{2} \mathrm{O}+\mathrm{O}_{2}\right)+\mathrm{CH}_{4}$ in $\mathrm{N}_{2}$ is converted to synthesis gas $\left(\mathrm{CO}+\mathrm{H}_{2}\right)$ over the temperature range of $973-1173$ $\mathrm{K}$ and at atmospheric pressure. The presence of $\mathrm{O}_{2}$ in the flue gas and concentration of hydrogen accumulation during the reaction significantly contributes towards a favorable thermodynamic profile for the reaction leading to a significant reduction in the activation energies of the various key reactions. The presence of oxygen in the flue gas shifts the overall process to an autothermal reaction scheme. The reaction also proceeds in a stoichiometrically balanced mode that restricts the reduction of rhodium to enable the formation of synthesis gas. The use of a $y$-alumina support impregnated with highly dispersed rhodium catalysts has helped address the urgent need to combat global warming and support a new generation of gas-to-liquids (GTL) scheme for the oxy$\mathrm{CO}_{2}$-steam reforming process and a new reactor to produce cost-effective synthesis gas $\left(\mathrm{H}_{2}\right.$ and $\left.\mathrm{CO}\right)$ have been developed. This work was part of the Climate Change and Emissions Management Corporation (CCEMC) of Canada Grand Challenge Round 2 awards in 2014. The project has demonstrated cost-effective utilization of greenhouse gases to generate value-added products. The research has been successful in proving the possibility of utilizing flue gas (without the necessity of separating the $\mathrm{CO}_{2}$ ) in a non-conventional reactor system having smoothed temperature profile due to the combination of exothermic (oxidation reaction) and endothermic (reforming reaction) in the same reactor. The reaction has been tested at 1 bar transmembrane pressure drop and at reaction temperatures from $973-1173 \mathrm{~K}$ and varying the space hourly velocity from 2.5 to $8.3 \mathrm{ml} / \mathrm{h} / \mathrm{g}$. Kinetic tests showed that the reaction order with respect to $\mathrm{CO}_{2}$ was 1.00 which we believe is pseudo-first order due to the presence of large dilution from the nitrogen present in the flue gas. On these bases this work is novel in the sense that the rhodium catalyst developed has been highly effective in converting the $\mathrm{CO}_{2}$ because it is highly dispersed in the pores of the membrane with force-flow characteristics, it has successfully achieved $90 \%$ conversion rate for both methane and carbon dioxide at a gas hourly velocity of $8.3 \mathrm{ml} / \mathrm{h} / \mathrm{g}$. At lower gas hourly space velocity, the conversion of both $\mathrm{CO}_{2}$ and $\mathrm{CH}_{4}$ was found to be slightly below $90 \%$ but the conversion of $\mathrm{O}_{2}$ remained constant at $100 \%$ as it was always completely consumed due to its high affinity for the active metal catalyst sites, hence making it react completely. Transport measurements have shown that there is not much there is not much segregation of the feed gas stream constituents in the membrane due to Knudsen diffusion. However, after the chemical reaction takes place, the produced $\mathrm{H}_{2}$ transported at a higher rate away from the reaction zone due to Knudsen separation of $\mathrm{H}_{2}$. This enhances the conversion of $\mathrm{CO}_{2}, \mathrm{O}_{2}$ and $\mathrm{CH}_{4}$ as a result of equilibrium-shift and thus increases the yield of syngas.

Nomenclature
Abbreviations
CMR
FTS
GHG
I.D
O.D
L

\section{Symbols}

$W_{R h}$

$W_{A I}$

J

F

Y

$\mathrm{t}$

A

$\alpha_{a / b}$

Qa/b (Knudsen)

M

\section{REFERENCES}

catalytic membrane reactor

Fischer-Tropsch synthesis

greenhouse gas

membrane support inner diameter

membrane support outer diameter

membrane support length

weight of the membrane after impregnation with $\mathrm{Rh}, \mathrm{g}$

weight of the membrane before impregnation with $\mathrm{Rh}, \mathrm{g}$

permeance, $\mathrm{mol} \mathrm{s}^{-1} \mathrm{~m}^{-2} \mathrm{~Pa}^{-1}$

molar flowrate, $\mathrm{mol} \mathrm{s}^{-1}$

gamma

thickness of membrane layer, $\mathrm{nm}$

surface area of membrane layer, $\mathrm{m}^{2}$

separation factor which is the ratio of the permeance of gas a to that of gas $b$

Knudsen selectivity of gas a over gas $b$ which is equal to the square root of the ratio of the molecular weight of gas $b$ to that of gas a

molecular weight of gas, $\mathrm{g} / \mathrm{mol}$ 
[1] Bermúdez JM, Fidalgo B, Arenillas A, Menéndez J. Dry reforming of coke oven gases over activated carbon to produce syngas for methanol synthesis. Fuel. 2010; 89(10):2897-2902.

[2] Wang Q, Chen X, Jha AN, Rogers $H$. Natural gas from shale formation-the evolution, evidences and challenges of shale gas revolution in United States. Renewable and Sustainable Energy Reviews. 2014; 30:1-28.

[3] Horn R, Schlögl R. Methane activation by heterogeneous catalysis. Catalysis Letters. 2015; 145(1):23-39.

[4] Paunović V, Zichittella G, Moser M, Amrute AP, Pérez-Ramírez J. Catalyst design for natural-gas upgrading through oxybromination chemistry. Nature chemistry. 2016; 8(8):803-809.

[5] McFarland E. Chemistry. Unconventional chemistry for unconventional natural gas. Science (New York, N.Y.). 2012; 338(6105):340-342.

[6] Bengaard HS, Nørskov JK, Sehested J, Clausen B, Nielsen L, Molenbroek A, et al. Steam reforming and graphite formation on Ni catalysts. Journal of Catalysis. 2002; 209(2):365-384.

[7] Dry ME. The fischer-tropsch process: 1950-2000. Catalysis today. 2002; 71(3):227-241.

[8] Bengaard HS, Nørskov JK, Sehested J, Clausen B, Nielsen L, Molenbroek A, et al. Steam reforming and graphite formation on Ni catalysts. Journal of Catalysis. 2002; 209(2):365-384.

[9] Keller G, Bhasin M. Synthesis of ethylene via oxidative coupling of methane: I. Determination of active catalysts. Journal of Catalysis. 1982; 73(1):9-19.

[10] Hinsen W, Baerns M. Oxidative coupling of methane to C2 hydrocarbons in the presence of different catalysts. ChemInform. 1983; 14(47).

[11] Rostrup-Nielsen JR. Catalytic steam reforming. Catalysis.: Springer; 1984. p. 1-117.

[12] Rostrupnielsen J, Hansen JB. CO2-reforming of methane over transition metals. Journal of Catalysis. 1993; 144(1):3849.

[13] Lunsford JH. The catalytic oxidative coupling of methane. Angewandte Chemie International Edition. 1995; 34(9):970980.

[14] Pakhare D, Spivey J. A review of dry $\left(\mathrm{CO}_{2}\right)$ reforming of methane over noble metal catalysts. Chemical Society Reviews. 2014; 43(22):7813-7837.

[15] Lan R, Irvine JT, Tao S. Ammonia and related chemicals as potential indirect hydrogen storage materials. International Journal of Hydrogen Energy. 2012; 37(2):1482-1494.

[16] Minardi ER, Chakraborty S, Curcio S. 4 - Membrane reactors for dry reforming of methane. In: Basile A, , Paola LD, Hai Fl, , Piemonte V, editors. Membrane Reactors for Energy Applications and Basic Chemical Production. : Woodhead Publishing; 2015. p. 99-144.

[17] Schlögl R. Catalytic Synthesis of Ammonia-A "Never-Ending Story"? Angewandte Chemie International Edition. 2003; 42(18):2004-2008.

[18] Wang ZX, Dong T, Yuan LX, Kan T, Zhu XF, Torimoto Y, et al. Characteristics of bio-oil-syngas and its utilization in Fischer- Tropsch synthesis. Energy \& Fuels. 2007; 21(4):2421-2432.

[19] Yang C, Ma Z, Zhao N, Wei W, Hu T, Sun Y. Methanol synthesis from CO 2-rich syngas over a ZrO 2 doped CuZnO catalyst. Catalysis Today. 2006; 115(1):222-227.

[20] Yin X, Leung DY, Chang J, Wang J, Fu Y, Wu C. Characteristics of the synthesis of methanol using biomass-derived syngas. Energy \& Fuels. 2005; 19(1):305-310.

[21] Kerr RA. Climate change. Global warming is changing the world. Science (New York, N.Y.). 2007; 316(5822):188190.

[22] Wang S, Liao X, Hu J, Cao D, Li Y, Wang J, et al. Kinetic aspect of CO 2 reforming of CH 4 on Ni (111): a density functional theory calculation. Surface Science. 2007; 601(5):1271-1284.

[23] Rostrupnielsen J, Hansen JB. CO2-reforming of methane over transition metals. Journal of Catalysis. 1993; 144(1):38-49.

[24] Gronchi P, Centola P, Del Rosso R. Dry reforming of $\mathrm{CH} 4$ with Ni and Rh metal catalysts supported on SiO 2 and La 2 O 3. Applied Catalysis A: General. 1997; 152(1):83-92.

[25] Pakhare D, Spivey J. A review of dry (CO 2) reforming of methane over noble metal catalysts. Chemical Society Reviews. 2014; 43(22):7813-7837.

[26] Djinović P, Batista J, Pintar A. Efficient catalytic abatement of greenhouse gases: methane reforming with CO 2 using a novel and thermally stable Rh-CeO 2 catalyst. International Journal of Hydrogen Energy. 2012; 37(3):2699-2707.

[27] Bartholomew CH. Mechanisms of catalyst deactivation. Applied Catalysis A: General. 2001; 212(1):17-60.

[28] Oyama ST, Lim H. An operability level coefficient (OLC) as a useful tool for correlating the performance of membrane reactors. Chemical Engineering Journal. 2009; 151(1):351-358.

[29] Lim H, Gu Y, Oyama ST. Reaction of primary and secondary products in a membrane reactor: studies of ethanol steam reforming with a silica-alumina composite membrane. Journal of Membrane Science. 2010; 351(1):149-159.

[30] Freeman B, Yampolskii Y, Pinnau I. Materials science of membranes for gas and vapor separation. : John Wiley \& Sons; 2006.

[31] Tong J, Matsumura Y. Pure hydrogen production by methane steam reforming with hydrogen-permeable membrane reactor. Catalysis today. 2006; 111(3):147-152.

[32] Patil CS, van Sint Annaland M, Kuipers J. Fluidised bed membrane reactor for ultrapure hydrogen production via methane steam reforming: Experimental demonstration and model validation. Chemical Engineering Science. 2007; 62(11):2989-3007.

[33] Gobina E. Apparatus and method for separating gases. 2006; US Patent 7297184.

[34] Gobina E., Hou k., Hughes R. A comparative evaluation of high-temperature membrane system for catalytic processing. Chemical Engineering Science. 1998; 166:157-181 